\title{
Quantitative Approaches to Sustainability Seminars
}

Rachel Levy

This article appears in celebration of Mathematics Awareness Month, an event sponsored annually in April by the AMS, the American Statistical Association, the Mathematical Association of America, and the Society for Industrial and Applied Mathematics. For 2013 the MAM theme is Mathematics and Sustainability. To find out more about MAM, visit the website http://www. mathaware.org/.

How can mathematicians contribute to education about sustainability? Mathematicians study climate change, energy-related technologies, models of energy availability, production and consumption, and even the political and social aspects of sustainable legislation and practices. However, at this point, few courses on sustainability can be found in mathematics department offerings. When we consider problems that our current and future students will face, energy sustainability certainly seems important. But how many of these ideas reach our classrooms?

We can incorporate sustainability into our existing courses through problem sets, projects, capstones, or independent studies. We can also reach a broad audience through the topical seminars offered at many colleges and universities. These seminars, sometimes specially designed for first-year students, tend to be characterized by small class size, discussion, and project-based learning, and perhaps by speakers and field trips. When students of all majors enter these courses they bring a wide range of mathematical preparation, confidence, and enthusiasm, which can make mathematical versions of these seminars challenging to design. A seminar in sustainability offered by mathematicians can provide students with an attractive path toward quantitative literacy. In this article I will explore how David MacKay's free online textbook, Sustainable Energy Without the

Rachel Levy is associate professor of mathematics at Harvey Mudd College. Her email address is 1evy@hmc.edu. DOI: http://dx.doi.org/10.1090/noti979
Hot Air (SEWTHA), could be used in a seminar to introduce students to principles of sustainability.

\section{Why Should Mathematicians Provide a Sustainability Seminar?}

We want students to be savvy consumers of quantitative information about sustainability in the popular and technical press. We also want them to apply their mathematical skills to model energy problems and solutions. To do so we must help them avoid common misconceptions such as "million=big" and "every little bit counts" that persist when communicators, policymakers, and readers fail to comprehend which magnitudes really matter. We also want mathematicians and their students who pursue technical research to be able to communicate how their particular focus of study (such as a climate change model) fits into the big sustainability picture. While the concepts in SEWTHA may differ from those in traditional mathematics curricula, MacKay's text has successfully provided students of varying mathematical backgrounds with a quantitative conceptual foundation regarding sustainability energy practices.

\section{A Free Online Text: Sustainable Energy Without the Hot Air}

Using only elementary mathematics, SEWTHA takes a quantitative perspective to give the reader context for further technical exploration of sustainability. The primary mathematical content in the energy calculations includes scaling, conversions between units, and estimation. Algebraic expressions appear in energy estimates but do not require much manipulation. Thus the text does not 
discuss traditional university mathematics topics. Instead it:

- demonstrates that any feasible plan for sustainability has to "add up"-that is, supply and demand must be balanced;

- bases simple and memorable quantitative estimates on underlying physical principles;

- promotes comprehension and retention through analogies between hard-to-grasp and wellunderstood quantities; and

- probes myths and misconceptions about energy and replaces them with factual rather than ethical assertions.

The first third of the text, "Numbers Not Adjectives", creates a two-column account balancing energy supply and demand. Each chapter adds to the balance sheet by expressing a type of production or consumption in terms of a common unit: energy in kilowatt-hours (kWh) or power in kilowatt-hours/day (where 40 watts $=1 \mathrm{kWh} / \mathrm{d}$ ). Major sources of demand include transport, heating and cooling, lighting, information systems and other gadgets, food, and manufacturing. The sustainable supply includes wind, solar, hydroelectric, wave, tidal, geothermal, and possibly nuclear energy sources. Most calculations boil down to the equation energy $=$ power $\times$ time (with the analogy to the equation volume $=$ flow $\times$ time ) and sometimes kinetic energy $=1 / 2 m v^{2}$. Technical questions are addressed as asides or at the end of the chapters in a question-and-answer format, along with an annotated bibliography.

The second third of the book focuses on the idea that "Every Big Helps". That is, unlike the conventional wisdom that "every little bit counts", the mathematics of sustainability demonstrates the unfortunate truth that if everyone only does a little bit to help, the sum of the efforts will address only a little bit of the problem. If we want to alter our behavior to improve energy sustainability, we need to understand which changes will make a significant dent in energy consumption. Then, through a series of calculations and comparisons, MacKay explains how we might significantly increase supply or reduce demand. For example, we might shift to electric vehicles with batteries charged by wind or solar.

The last part of the book, called "Technical Chapters", revisits the items on the balance sheet from the first chapters and reviews how the technologies might be improved. The mathematical details are still fairly simple but discuss energy concepts such as force and efficiency in addition to power. For example, in heating a structure, power used $=($ average temperature difference $\times$ leakiness of the building)/(efficiency of heating system). More advanced undergraduate topics such as a partial differential equation (the heat equation) appear as supplementary information.
Throughout the book, SEWTHA focuses on calculations for the UK, which provides an interesting opportunity for students to pursue similar calculations for a region of interest. Because many issues of feasibility relate to population density, students performing the same types of calculations might reach conclusions different from those in SEWTHA. The text explicitly does not deal with some important aspects of sustainability, such as economic feasibility and social acceptability, and only touches on the issue of environmental impact. These questions are put aside in favor of a quantitative view, which can be seen as a prerequisite for tackling the other aspects of the problem.

\section{Assignments for a Sustainability Seminar}

To envision a sustainability seminar using SEWTHA, I have designed assignments in four categories: calculation, discussion, communication, and invention. As MacKay notes, convictions are stronger if they are self-generated rather than taught, so each of the projects is structured to help students form and develop ideas about sustainability rather than simply receive them.

Calculation: Students can perform similar calculations in a new context. Completing the following types of studies and comparisons can provide students with a meaningful sense of the scale of the energy issues and sustainable solutions.

1. Redo calculations for a geographic region of interest. For example, calculate the cost of air conditioning/heating in different parts of the United States using average daily temperatures.

2. Estimate each student's yearly energy consumption.

3. Compute the energy per trip required for some car/bus/train trip the student has made regularly. Compare this energy to some other activity.

4. Calculate the area required for energy production installations based on some physical dimension the student knows well (home acreage, soccer field, campus).

5. Choose a vacation destination that would require air transport. Choose a favorite electronic gadget. Compare the energy cost between the transportation and the powering of the gadget.

6. Figure out which gadgets in the dorm or college "suck" the most energy. Buy a meter to determine which devices (sometimes known as vampires) require the most energy when they are "off".

7. Conduct a lifecycle assessment of both energy requirement and use for a product or system.

8. Compare the lifecycle assessments for multiple ways to accomplish the same task (such as landscaping a yard).

Discussion: Through discussion and debate, students can wrestle with the choices required to create and achieve sustainability goals. Discussions 
can be facilitated by groups of students who, in advance, prepare ways to stimulate the conversation.

1. Discuss a chapter from the text or a related (and perhaps more mathematically focused) article.

2. Identify and discuss both factual and ethical assertions in popular (and perhaps scientific) articles.

3. Debate the pros/cons and viability of various energy options, such as solar versus wind.

Communication: Student projects can focus on communicating the messages of MacKay's book, or their own ideas about mathematics and sustainability.

1. Choose a quantitative myth about sustainability and develop a way to communicate the misconception and truth to the public (such as a memorable cartoon, graphic, or video).

2. Extract/write/share the underlying principles and take-home messages of a particular chapter.

3. Design an outreach activity (perhaps a game) that would help kids explore some ideas from the text about mathematics and sustainability.

4. Identify a misleading idea communicated in a popular article. Write a press release or advertisement refuting the misconception and promoting the facts. Address how the misconception could affect public opinion in a harmful way.

Invention: Students can investigate and develop ways for current businesses, common practices, and systems to be made more sustainable. Projects that involve real clients can motivate hard work and innovation.

1. Learn how a local company performs energy audits. Then perform an energy audit for a local business and make some recommendations to significantly improve sustainability practices of the business.

2. Consider a common practice at the college or university and determine a feasible plan to make the practice more sustainable. Examples include food usage, garbage/recycling practices, energy use, transportation.

3. Create a new way to take advantage of an existing or new technology.

Many more ideas for discussion topics and projects can be found online. An example of a nice companion to MacKay's book has been developed as a freely available online course through Clemson (see reference below).

As a mathematician, when I first read SEWTHA, I was hoping to find material that I could directly incorporate into my existing courses. Instead, I gained a new quantitative perspective on sustainability to keep in mind when considering technical information in the future. If I decide to pursue a new avenue of research related to sustainability, I will make my choice with a better understanding of the potential impact of my work on society. At the same time, I am inspired to offer a quantitative course, accessible to many students, using SEWTHA as a starting point. I hope to hear from those of you who choose to do the same.

\section{Acknowledgments}

I would like to thank David Keffer of the University of Tennessee, Leidy Klotz of Clemson University, Erin Byrne of Olin College, and Ellen Swanson of Centre College for helpful conversations.

\section{Mathematical Reading and Resources}

Many syllabi, articles, datasets, and other resources can easily be found online. The SEWTHA website itself contains materials for teachers. References for a few additional resources are included here.

1. The National Renewable Energy Lab (NREL) website contains datasets, publications, and contact information for potential speakers, http:// www.nre1.gov/.

2. Free online course materials developed by Leidy Klotz at Clemson are available at https:// canvas.instructure.com/courses/593350.

3. Online resource for mathematical modeling and sustainability, http://home.comcast. net/ benfusaro/Book/FrontMatter.htm1.

4. Mathematical Modeling of Earth's Dynamical Systems: A Primer, by Rudy Slingerland and Lee Kump, Princeton University Press, 2011.

5. United Nations report on sustainability, http://www . un .org/Depts/dh1/resguide/ specenv.htm\#commission.

6. A Joint Initiative of the North American Mathematical Institutions: Climate Change, Sustainability and the Mathematical Sciences, http://www. mathinstitutes.org/climate-initiative/. 